\title{
Towards a Critical Theory of the Technosystem
}

Andrew Feenberg, Technosystem: The Social Life of Reason, Harvard University Press, 2017, 235 pp., ISBN 9780674971783, James Bridle, New Dark Age: Technology and the End of the Future, Verso, 2018, 294 pp., ISBN 9781786635471, and Taina Bucher, If...Then: Algorithmic Power and Politics, Oxford University Press, 200 pp., ISBN 9780190493035

\section{Raphaël Wolff ${ }^{1}$}

Published online: 10 December 2019

(C) The Author(s) 2019

\begin{abstract}
Feenberg's new book, Technosystem: the social life of reason, makes an important intervention in the study of technological systems by showing that instrumental reason requires value judgement at the moment of its realization in this world. It fosters hope that technological development can be redirected towards the fulfilment of human needs through public interventions of nonexperts. However, Feenberg does not sufficiently engage with the political dilemmas that inevitably accompany these interventions as a result of the formal capitalist bias of the technosystem. The books by Bridle and Bucher underline the importance of confronting these dilemmas as they encounter them in various domains and provide possible ways for dealing with them.
\end{abstract}

Keywords Reification · Politicization · Technology · Instrumental reason · Capitalism · Big data

\section{Introduction}

Climate change, the erosion of privacy, and the insatiable data hunger of governments and businesses, they all express a growing concern over the reach and direction of what Andrew Feenberg calls the technosystem: 'a field of technical practices aimed at control of the environment, whether natural, economic, or administrative'. ${ }^{1}$ In our online world of big data, it has become all-encompassing. Indeed, computation and information processing saturates all

${ }^{1}$ Feenberg 2017, 159.

Raphaël Wolff

rbbw2@kent.ac.uk

1 University of Kent, Brussels, Belgium 
aspects of our lives and is driven by the ambition of individuals, governments, and businesses 'to raise awareness of some everyday circumstance [...] for analysis and response'. ${ }^{2}$ Confronted with the effects of the technosystem, more and more people voice their concern about the discrepancy between what technological systems do and what we want from them. Increasingly, people are aware of the empty promise that scientific and technical advances would bring moral progress in addition to material progress. ${ }^{3}$

The problem is that 'those in command condemn public demands for change as irrational'. A division between technical experts and laypeople hinders public efforts to change the technosystem, kept in place by the hegemony of instrumental reason. Complicating matters even further, this is codified in the very design or infrastructure of the technosystem, making the power exerted by technologies almost invisible. ${ }^{5}$

Feenberg stages an intervention by demonstrating that 'the technical is always already cultural' and '[r]ationality enters the social world socially'. ${ }^{6}$ In other words, technology cannot be realized without answering to social demands. He is careful not to eliminate or replace instrumental reason, afraid of throwing out the baby with the bathwater. After all, '[m]odern society is so completely technified that a return to "nature" is inconceivable'. It would merely open the door to spiritualism or fundamentalism as romantic alternatives to modernity. Instead, he explores the progressive possibilities residing in 'effective communication between lay and expert actors', between 'public protest and technical implementation'. ${ }^{8} \mathrm{He}$ looks for a gestalt switch from within the technosystem that establishes the rationality of public struggle over the technological design of society, opening up a new horizon of possibilities for the direction of its development.

It is an ambitious programme, which requires the reformulation of rationality, the role of technology in society, critique, and progress. This review zooms in on these efforts, celebrating Feenberg's achievements and using the work of James Bridle and Taina Bucher-themselves impressive and thought-provoking books - to identify areas where questions remain and more work is needed. More specifically, Feenberg does not sufficiently engage with the political dilemmas that inevitably accompany public interventions of nonexperts as a result of the formal capitalist bias of the technosystem. These dilemmas concern how the technosystem warps the political expression of social demands, keeping its formal bias intact.

\section{The 'Double Aspects' of Instrumental Reason and the Functionalization of Society}

Feenberg organizes his book in an unconventional way. He starts with a discussion of his method, which he calls critical constructivism. Then, he applies it to the Internet, showing the multiplicity of technologies and the open and revisable character of their designs. The theory comes after. This is peculiar because Feenberg's theoretical revision of instrumental reason

\footnotetext{
${ }^{2}$ Greenfield 2018, 32 .

${ }^{3}$ Feenberg 2017, 129.

${ }^{4}$ Ibid., 116.

5 Ibid., 190, 194.

${ }^{6}$ Ibid., 114, 153, emphasis removed

7 Ibid., 160.

${ }^{8}$ Ibid., 114.
} 
touches on every aspect of his account of the technosystem, rippling through the entire argument. It forms the well-spring of his critical theory of technology.

In order to make critique possible from within the technosystem, Feenberg tries to update the premises of Frankfurt School Critical Theory as formulated by Adorno, Horkheimer, and Marcuse. ${ }^{9}$ He argues that these thinkers have been unable to formulate an adequate critique of the technosystem because they did not work with an adequate understanding of instrumental reason - courtesy of Max Weber's account of modernity and rationalization. ${ }^{10}$

Weber recognized the historical dilemma of modernity. The rise of instrumental rationality gave individuals the means to break the hold traditional worldviews had over them. At the same time, it revealed ends and values as 'mere conventions about which opinions legitimately differ'. ${ }^{11}$ This rationalization process had two outcomes. First, it resulted in the 'warring of the gods' or the never-ending competition between different value systems. Second, in the absence of a generally recognized principle, the application of technique to nature and society was left to its own devices, having only the increase of its own efficiency and power as its end. Weber characterized this as man's 'iron cage', reducing individuals to merely cogs in a machine.

The first generation Frankfurt School thinkers had a keen eye for how this process developed in the early and mid-twentieth century, especially focusing on its negative implications. Indeed, 'Adorno came to the ominous conclusion that experience in advanced capitalism was so corrupted by commodification and the mass media that it could no longer provide a touchstone of alternative values'. ${ }^{12}$ However, they did not see the progressive promise contained in rationalization.

Drawing on the work of Ian Angus, Feenberg shows that a connection persists between the experiences of people in everyday life, or the life world, and the technical system that abstracts from them. Although much context information is lost in the formalization of means and ends, the 'formation of means/ends complexes in modernity is the outcome of implicit judgements that identify potentials in the lifeworld'. ${ }^{13}$ In other words, instrumental reason consists of an interpretive act that necessarily involves some sort of value judgement in order to enable technical specification in the first place.

It is hard to overstate the importance of this insight, not just for Feenberg's argument, but for the entire promise that his account of the technosystem contains. While instrumental reason seems to have swallowed us whole, locking us in Weber's iron cage forever, Feenberg shows that it is not a detached force beyond our influence. Instead, it depends on a connection to the lifeworld that cannot be severed. As such, values do not reflect an external force that competes with instrumental reason and assails it from the outside. Instead, they constitute a necessary element in the realization of rationality in this world.

This revision of instrumental reason supports Feenberg's instrumentalization theory, which provides an account of the way people build technological systems. He developed this theory in earlier work to 'account for functionality as a social phenomenon'. ${ }^{14}$ It is based on the fact that objects only become technical when people assign it a certain function. This 'requires the decontextualization of relevant aspects of the object of technical control and its association

\footnotetext{
${ }^{9}$ Ibid., 41.

${ }^{10}$ Ibid., 121.

11 Ibid., 130.

12 Ibid., 132.

13 Ibid., 131.

${ }^{14}$ Ibid., 153.
} 
with other similarly decontextualized objects to form a technically coherent system' ${ }^{15}$ Crucially, it involves judgement at the constitutive choice for identifying particular aspects of objects as functions. ${ }^{16}$ In other words, the functionalization of technologies replicates and embodies the dual aspects of instrumental reason.

The result of this process is a 'design code', which 'identifies the larger social meaning of technical designs, the stabilized intersection of social choice with technical specification' ${ }^{17}$ It reflects the translation of values into functions at the very inception of technologies. Importantly, this means that the technosystem - as the embodiment and expression of instrumental reason - has both a factual and a normative aspect, containing the spaces for alternative values and therefore the very sources for its transformation. This shifts the focus to the political struggle over the values realized in technological design.

\section{A Critical Constructivist Approach to the Technosystem}

In order to make technological politics visible, Feenberg crafts a methodological approach he calls critical constructivism. Three concepts stand out in that approach: underdetermination, concretization, and formal bias.

Feenberg draws on the empirical richness of science and technology studies (STS) to argue that politics stands at the heart of technological development. The fine-grained case studies in STS demonstrate that design codes are the outcome of contingent struggles between conflicting understandings of a problem for which actors seek a technological solution. This means that technologies are underdetermined, which 'leaves room for social choice between different designs that have overlapping functions but better serve one or another social interest'. ${ }^{18}$ The success of certain designs over others is therefore not a result of their superior efficiency or effectiveness. Indeed, '[s]tandard technical categories such as "working" and "not working," "efficient" and "inefficient," are understood in terms of social demands and perceptions'. ${ }^{19}$ What these terms come to mean in technical specification depends on how the struggle over design code unfolds.

It is an important insight that reveals the double aspects of instrumental reason as a social and political dynamic at the heart of technologies. However, Feenberg worries it might reduce technology to merely the outcome of power struggles, leaving technical objects without any power of their own. He finds an antidote for this in the work of Simondon.

Simondon's notions of technicity and concretization draw attention to the power of technical objects. According to Simondon, technologies not only develop in line with changing human needs, but also are based on an intrinsic logic detached from considerations of use and function. He called this the technicity of technologies. When a technology is able to satisfy an increasing number of external functional demands and reduces the number of components needed to do so at the same time, it achieves concretization. ${ }^{20}$ Feenberg argues this provides a new idea of technical progress, which depends on technologies achieving internal coherence and synergy with the environments in which they operate. It shows that struggle over design

\footnotetext{
${ }^{15}$ Ibidem.

${ }^{16}$ Ibid., $153-154$.

17 Ibid., 56.

18 Ibid., 46.

19 Ibid., 70.

${ }^{20}$ Ibid., 71-72.
} 
codes and progress based on ideas of efficiency can coexist, constructing 'alliances among the actors whose various demands are materialized in a single object'. ${ }^{21}$ Crucially then, '[i]dentifying such advances validates a democratic politics of technology'. ${ }^{22}$

These advances are not guaranteed, however. A truly critical account of the technosystem has to explain why the technosystem is skewed towards its own reproduction; that is, how instrumental rationality shapes social interests and comes to pervade all aspects of our lives in the first place. On their own, STS and Simondon cannot address 'the principal insight of the Frankfurt School — namely, the role of capitalism in the cultural generalization of instrumental rationality'. ${ }^{23}$ This requires a notion of technical power, which Feenberg finds in Marx's insights about formal bias.

Marx noted something peculiar about how the capitalist system worked. The market appeared rational - based on the exchange of equivalents facilitated by money - but only enriched the owners of the means of production while workers were stuck at subsistence level. This was not a matter of discrimination, because workers got exactly what their hours were worth on the labour market. In other words, it was not a substantive bias. Instead, the bias was part of how the market worked, which adhered to capitalist imperatives. Through the concept of formal bias, Marx showed how bias and rationality could coexist and how 'the design of the system objectifies the discriminatory principle'. ${ }^{24}$

Technology plays a key role in how the system objectifies its discriminatory effects as Marx already observed. When labour becomes wage labour, 'its tasks are simplified and parceled out'. ${ }^{25}$ This continues with mechanization - or the replacement of workers with machineswhich 'transforms concrete labor into abstract and measurable units of labor power that can be supplied by anyone'. ${ }^{26}$ In other words, the technological design of the production process in the factory encodes the principle that makes the market look rational- the exchange of equivalents.

Feenberg enlists Foucault's notion of power/knowledge to generalize these findings to other domains in society based on an affinity between Foucault's and Marx's methodological approaches to modern society. ${ }^{27}$ Power and knowledge are entangled, creating objects and subjects as fields of intervention and inspection. Technologies encode and materialize these entanglements, holding in place 'a web of social forces and tensions in which everyone is caught as both subject and object' ${ }^{28}$ As such, the rise of technical disciplines like criminology, psychiatry, and the administrative sciences along with their technologies of power can account for the production of subjects endowed with instrumental reason and the desire of these subjects to objectify it in technologies. The panopticon and the prison are an example of this. ${ }^{29}$ While such a link between these thinkers is intuitively compelling, it could have benefited from a more extensive discussion of Foucault's work on power and its conceptual trajectory from discipline to governmentality, as well as how he developed and understood his methodological approach. ${ }^{30}$

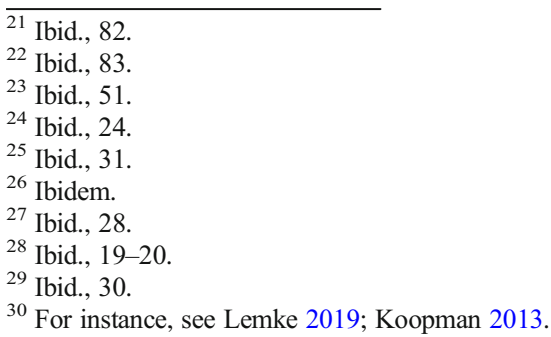


The critical constructivist approach that Feenberg presents is one of hope. It attunes itself to the identification of instances of concretization in which even actors with competing social demands work together towards a common technological future. As such, they provide openings to identify and question formal biases encoded in the system. This is not idle hope because the 'residue excluded by functionalization comes back to haunt technical achievements where they fail to take into consideration the most significant dimensions of their objects and contexts'. ${ }^{31}$ As Feenberg shows, this is the source for a socio-technical notion of progress and comes from within the technosystem.

\section{Progressive and Critical?}

However, there is ambivalence to the notion of technological progress that Feenberg derives from Simondon's notion of concretization. Progressive is not necessarily critical as it is understood in Critical Theory. Feenberg alludes to this distinction and its implications for politics, but does not sufficiently engage with it. At the root of this problem is his contention with Habermas, which opens up new ground for immanent critique as much as it raises critical questions.

Habermas distinguishes between two broad domains in society, system and lifeworld. The former is ruled by instrumental rationality while the latter is founded on communicative rationality, which refers to the ability of people to let the force of the better argument guide them to a rational consensus despite their differences. According to Habermas, the problem with modern society is the intrusion of instrumental rationality in domains of life where it does not belong. In principle, there is nothing wrong with this type of rationality, as long as it stays within bounds. As Feenberg notes, '[t]his dualistic framework continues the critique of domination of the early Frankfurt School while rejecting its totalizing, dystopian conclusions. 32

This comes at too great a cost, however. According to Feenberg, it implies an essentialist and neutral conception of instrumental rationality, which cannot account for the way the technosystem structures perception and subjective experience - a phenomenon Lukács called reification. ${ }^{33}$ In other words, Habermas cannot explain why instrumental rationality colonizes the lifeworld in the first place. Indeed, Feenberg brings the work of Lukács and STS together to argue that instrumental rationality has a bias towards the creation of a technical society and that public interventions play a decisive role. ${ }^{34}$ The dualistic framework renders invisible the constitutive link between instrumental reason and the lifeworld; that is, how 'instrumental and communicative rationality interpenetrate in all institutional settings' ${ }^{35}$ As such, Habermas cannot see the struggles that take place in the technological domain as both constitutive elements in the technosystem and promising avenues to pursue emancipation across domains.

Although Feenberg discusses Luckács at some length throughout the book - and relies on him to go beyond Habermas - he does not update his work to our present day. This opens a line of critique that demands a more extensive account of politics in the technosystem than Feenberg provides. As Chari argues, Marx's work on alienation and Luckács's work on reification reveal that 'while in neoliberal capitalism subjects may appear to be active,

\footnotetext{
${ }^{31}$ Feenberg 2017, 160.

32 Ibid., 42.

33 Ibid., 148-152.

${ }^{34}$ Ibid., 43-45.

35 Ibid., 44.
} 
involved, and innovative, rather than passive and disengaged', neoliberal subjectivity still fragments subjective experience. Doing so, it reinforces the perception of closed-off and distinct domains in society like the economy and politics. ${ }^{36}$ Unless consciously directed at these boundaries, critical reflection and action reinforces reified categories, as Habermas does by grounding his critique of modernity on the distinction between lifeworld and system. The same holds for resistance and contestation. Although Feenberg targets the boundary between instrumental and communicative rationality, he stops short of discussing how to deal with the ambivalence of contestation that results from reification. This ambivalence stands at the heart of his account of rational public intervention in technology.

According to Feenberg, the realization of instrumental reason in functional technologies requires an interpretive moment that takes the form of judgment, conjoining fact and value. More specifically, this is reflective judgement, which involves a process of specifying a general rule on the basis of a particular case. Crucially, as Kant showed in his discussion of judging beauty, this presupposes an appeal to others in a process of making sense in common. The result is an enlarged mentality or agreement on an objective standpoint on a matter. ${ }^{37}$ Arendt argued that politics also involves reflective judgement, providing an alternative to Habermas's particular conception of communicative rationality. ${ }^{38}$ This provides the rational basis for public intervention in technological design, as reflective judgment on technological design transforms social interests into rational claims in order to attain an 'enlarged technical mentality'. 39

Feenberg relies on Azmanova's elaboration of Arendt's reflection on political judgement to flesh this out. ${ }^{40}$ She argues that the appeal to others in political judgment proceeds on the basis of shared notions about what constitutes a relevant concern for public debate and political action. This 'phronetic background' enables debate as it concerns a common ground of orientations or disagreement within agreement. She notes that people learn these categories of relevance through shared social practices. This means that grievances or experiences of injustice have to be expressed in a certain way to become political concerns. Although the orientations develop over time in response to outcomes of contestation and alter the boundaries of validity, they seem to have a conservative force. However, under certain conditions, it can lead to an enlarged mentality with critical potential, disclosing socio-historical patterns of injustice to the participants in the debate.

In the technosystem, this background consists of rational operations. Based on the doubleaspect theory of instrumental reason, Feenberg argues that experts employ refined versions of rational operations that exist in the lifeworld. He gives the example of decontextualization used in functionalization, which is a form of interpretation in the lifeworld. ${ }^{41}$ This means that '[r]ationality is distributed across the lines dividing expert from lay and facts from values'. ${ }^{4}$ As such, '[e]xperience within the technosystem assumes a rational form capable of interacting with technical expertise'. ${ }^{43}$ When people have negative experiences with technologies, these

\footnotetext{
${ }^{36}$ Chari 2015, 113.

${ }^{37}$ Feenberg 2017, 164.

38 Ibid., 165.

${ }^{39}$ Ibid., 167.

40 Azmanova 2012.

${ }^{41}$ Feenberg 2017, 168, 179.

42 Ibid., 134.

43 Ibid., 202.
} 
grievances trigger debate that proceeds on the basis of these rational operations. ${ }^{44}$ This opens up technologies for re-evaluation, possibly resulting in an enlarged technical mentality about the social demands that technologies have to consider in their design. This sets the stage then for concretization to happen and technological progress to occur. ${ }^{45}$

However, formal bias introduces a complicating factor in the prospect of progress and Feenberg's argument. Technologies encode and materialize the discriminatory principles of the capitalist system in the very infrastructure of society. This entails that formal bias enters the phronetic background through social practices involving technologies. It also encodes the reified boundaries that Feenberg wants to challenge. Indeed, that is the reason why contestation over technology has to proceed in terms of rational operations and reified boundaries persist at the level of discourse. ${ }^{46}$ Therefore, it cannot be assumed that successful public interventions in technologies target formal bias. Feenberg seems to do so when he says that critical constructivism 'situates struggles over the technosystem in a larger historical context in which the imperatives of capitalism have determined criteria of technical advance contested by democratic interventions'. ${ }^{47}$

To be sure, Feenberg notes that challenging substantive biases is not enough and that public interventions should make the connection between a particular grievance and the impersonal power of technology. ${ }^{48}$ But what if rational operations, as the language of contestation, move people away from formal bias towards substantive bias, even if it concerns the design of technologies? This can lead to what Azmanova has called the 'emancipation paradox': a situation when successful contestation also enhances the validity of the system by conferring value on it as the framework in which to achieve success. ${ }^{49}$ While she uses a different terminology, this works the same way with substantive and formal bias. Feenberg acknowledges this possibility by saying that public protests only have an impact if dialogue between experts and laypeople remains 'within the general framework of the modern understanding of rationality' ${ }^{50}$ It also follows from updating Lukács's work on reification to the present day as Chari has shown.

This suggests that Feenberg's critical constructivism remains incomplete without an account of how public interventions enlarge a society's technical mentality. This is not just an empirical question that requires the detailed study of progressive movements and their challenges of technology. It also necessitates theoretical reflection on how contestation changes and enlarges the meaning of rational operations and what this entails methodologically. The books by Bridle and Bucher underline the importance of doing so.

\section{A New Dark Age}

The essays in James Bridle's latest book read like cautionary tales about the technosystem run amok, providing a catalogue of the blind spots in technological progress. Bridle locates the

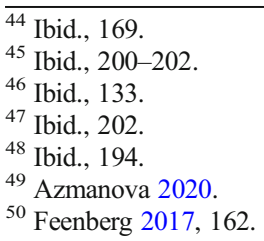


problem in the central idea of the Enlightenment: 'that more knowledge - more information leads to better decisions'. ${ }^{51}$ In particular, he focuses on computational thinking or 'the belief that any given problem can be solved by the application of computation' ${ }^{52}$ This has achieved such dominance in the world that it becomes almost 'impossible to think or articulate the world in terms that are not computable'. ${ }^{53}$ A new dark age looms: 'an age in which the value we have placed upon knowledge is destroyed by the abundance of that profitable commodity'. ${ }^{54}$ Instead of enlightening us, it darkens the world.

Bridle's reflections underline the importance of thinking through the possibilities for politics once it has become a rational element in the technosystem. As Feenberg noted-but did not problematize enough - the technosystem shapes how people experience, negotiate, and question it, enabling certain actions while constraining others. Inductively, Bridle demonstrates that computational thinking constrains technological politics in two ways. First, it fosters a new illusion of control that seduces people away from politics and preserves the supposed neutrality of technology. Second, it domesticates critique by shaping the very language and logic of contestation.

Seeing it as a form of hubris, Feenberg defines technological action as a way to cheat the world and escape the immediacy of causal feedback. ${ }^{55}$ However, as natural beings, no one can escape these feedback effects, raising the question how to deal with them. Bridle shows that our best answer has been more technological action, spurred on by the promise of a deeper understanding of the world contained in computation.

However, the reduction of reality to computable variables creates the conflation between approximation and simulation, replacing the world with flawed models. ${ }^{56}$ But with the belief in infinite exponential growth of computational power, reduction has given away to adding information to make models more accurate. Today this has even reached the point that people think models are not needed anymore. With enough data and strong enough computers, the numbers will speak for themselves. This is the promise of big data. ${ }^{57}$ The result, Bridle warns, is that we are becoming computers ourselves: 'As computation and its products increasingly surround us, are assigned power and the ability to generate truth, and step in to take over more and more cognitive tasks, so reality takes on the appearance of a computer; and our modes of thought follow suit'. 58

As long as we can extract enough data to satisfy this demand for information, the illusion of control remains intact. However, this increasingly reaches its limit. Bridle's essay about global warming is especially telling and unsettling. As rising temperatures melt away the permafrost at an accelerating rate, archaeologists in the Arctic regions engage in a race against the clock to access the geological past in order to gain information that could help us in fighting global warming. It shows that ' $[t]$ he certainties of the present are founded on the assumption of everincreasing, ever-crystallizing geologies of knowledge'. ${ }^{59}$ Literally turning into mush, the sources of data slip away and with them the past as our surest guide to the present and future. As such, the melting permafrost and the actions of the archaeologists provide a metaphor of

\footnotetext{
${ }^{51}$ Bridle 2018, 10, emphasis removed.

52 Ibid., 4

${ }^{53}$ Ibidem.

54 Ibid., 11.

55 Feenberg 2017, 3

${ }^{56}$ Bridle 2018, 34.

${ }^{57}$ Ibid., 81-84.

58 Ibid., 43.

59 Ibid., 58.
} 
our collapsing cognitive infrastructure and the limits to the belief that more information is always better.

The problem of computational thinking also besets politics, as Bridle's discussion of the controversy over mass surveillance after the Snowden revelations demonstrates. In the investigations, hearings and debates that followed, time and again it was shown that digital mass surveillance is not effective. It actually swamps analysts with too much information as President Obama acknowledged after a failed attack aboard a flight from Amsterdam to Detroit. ${ }^{60}$ Bridle argues that the call for more transparency - often heard in the wake of the revelations - only inverts the same surveillance logic. More specifically, it centres on the belief 'that there is some secret at the heart of the world that, if only it can be known, will make everything better'. ${ }^{61}$ It fosters a search for the 'smoking gun', the single piece of evidence that brings down an enemy or an authority. Bridle warns that the outcome is political apathy when that threshold of truthfulness is not attained: 'The demand for some piece of evidence that will allow us to assert some hypothesis with 100 per cent certainty overrides our ability to act in the present'. ${ }^{62}$ The political dynamic of the controversy is an example of how the logic of the technosystem dictates how we can respond to it. While it ensures that public interventions are rational, more is needed than just an enlarged technical mentality to disclose and question the system's formal bias. This also requires a change in the terms of contestation fostered by the technosystem.

Similar to Feenberg, Bridle contemplates change from within as he too realizes that the technosystem has become all-encompassing: We are 'utterly enmeshed in technological systems', unable to stand outside or think without them. ${ }^{63}$ It requires us to rekindle the politics of technology, negotiating anew the relations to the world that technology facilitates. Indeed, [o] ur technologies are extensions of ourselves, codified in machines and infrastructures, in frameworks of knowledge and action; truly thought, they offer a model of a truer world' ${ }^{64}$ The prospect of a new dark age urges us to do as much.

\section{Beyond the Black Box}

Focusing on the power and politics of algorithms, Bucher's work provides an impressive example of integrating a sensibility for struggle over design with the particular politics technological systems make possible. For Bucher, algorithms have become a cultural logic, 'drifting into the ways in which people think and talk about everything from the economy to knowledge production to culture'. ${ }^{65}$ This makes algorithms much more than 'a step-by-step guide that prescribes how to obtain a certain goal, given specific parameters'. ${ }^{66}$ Algorithmic power goes beyond what it does technically and refers to the way it produces 'certain forms of acting and knowing' and generates certain 'kinds of encounters and orientations'. ${ }^{67}$ This also

\footnotetext{
60 Ibid., 180-181.

${ }^{61}$ Ibid., 183.

62 Ibid., 184.

${ }^{63}$ Ibid., 2.

64 Ibid., 15.

65 Bucher 2018, 39.

66 Ibid., 21.

${ }^{67}$ Ibid., 3.
} 
entails politics, which Bucher understands as 'the way in which some realities are always strengthened while others are weakened'. ${ }^{6}$

Bucher fleshes this out with her notion of algorithms as eventful. The politics and power of algorithms only come into being as part of a configuration consisting of social and technical elements which have 'the capacity to produce certain orderings and disorderings in the world'. ${ }^{69}$ It is in these interactions that certain realities emerge. This shifts attention away from questions about what algorithms are to when and how they matter and exert their influence. She draws on Foucault's notion of governmentality to show that the design of algorithmic systems governs the possible field of action of its users by shaping them as specific subjects. ${ }^{70}$ For example, her first case study on the Facebook newsfeed algorithm demonstrates that it produces a participatory subjectivity. Facebook wants to maximize engagement with its platform in order to generate more revenue, so it is designed to make users participate, communicate, and interact as much as possible. The newsfeed algorithm achieves this by 'emphasizing those stories that generate a lot of comments and likes', which makes it 'appear as if everybody is participating and communicating, ${ }^{71}$ It sets participation as the norm. The algorithm reinforces a certain regime of visibility as it learns from users what activities and posts are popular and increase engagement, adjusting its code in a way that enhances the probability of users becoming visible through such activities. ${ }^{72}$ As such, the platform creates the threat of invisibility and shapes what kind of behaviour makes people visible on the platform. ${ }^{73}$ Doing so, it works like an inverse panopticon.

The eventfulness of algorithms is not restricted to the materialization of a particular design, but also includes the interactions that people have with such systems. As Bucher argues, 'algorithms do not just do things to people, people also do things to algorithms' ${ }^{74}$ Drawing on interviews with social media users, Bucher mapped 'the moods, affects, and sensations of which algorithms are generative', detailing when and how algorithms came to matter to the users. ${ }^{75}$ More specifically, their personal stories reveal 'an algorithmic imaginary-ways of thinking about what algorithms are, what they should be, how they function, and what these imaginations, in turn, make possible'. ${ }^{76}$ This attains a particular significance with machine learning, which entails that 'algorithms are continuously molded, shaped, and developed in response to user input'. ${ }^{77}$ While the design of an algorithmic system shapes the possible actions of users, people's 'beliefs, experiences, and expectations of what an algorithm is and should be' affect this 'programmed sociality' of social media platforms. ${ }^{78}$ Even if they do not rise to the level of contestation, practices of everyday negotiation and resistance mattersomething that Feenberg mostly ignores.

Perhaps most interesting for advancing the line of critique of Feenberg's work is Bucher's discussion of the 'conditions under which algorithms become objects of concern'. ${ }^{79}$ Her case

\footnotetext{
${ }^{68}$ Ibidem.

${ }^{69}$ Ibid., 16.

${ }^{70}$ Ibid., 36-38.

71 Ibid., 89.

72 Ibidem.

${ }^{73}$ Ibid., 84-88, 92.

74 Ibid., 94.

75 Ibid., 97, 100.

76 Ibid., 113.

77 Ibid., 95.

78 Ibid., 114.

79 Ibid., 120.
} 
study on the reactions of Scandinavian newspapers to a news environment mediated by algorithms provides the empirical backdrop for this discussion. Her interviews show that 'algorithms are judged, made sense of and explained with reference to existing journalistic values and professional ethics'. ${ }^{80}$ They are experienced as problematic when they challenge editorial responsibility to provide readers with information that they should know, even if that involves giving them the opposite view of an issue. The interviewed journalists thought that too much automation interferes with maintaining a professional journalistic environment, eroding the human judgement needed to do so. ${ }^{81}$ As such, the inevitability of a hybrid media system forces newspapers to reflect on 'existing boundaries of what journalism is and ought to be' and how interaction with algorithms will reflect the right (and reconsidered) values. ${ }^{82}$ It demonstrates that algorithms problematize practices and become problematic within them. Importantly, it draws attention to the way the encounter with algorithms and its particular setting shape our orientations towards them, providing an opening for a change in the phronetic background that enables political judgement. ${ }^{83}$ Feenberg alludes to this opening, but does not provide the methodological tools to fully account for the role of technology as problematizing devices - something that a more extensive discussion of Foucault could have provided.

According to Bucher, algorithmic culture - and therefore its phronetic background - also extends to approaching algorithms methodologically. This concerns the metaphor of the black box in particular. Algorithms are often criticized for hiding away crucial decisions behind a veil of code, and the metaphor of the black box acts as a vehicle for claims of transparency. ${ }^{84}$ More precisely, it is used to problematize the discriminatory effects of algorithms, seemingly challenging the formal bias that Feenberg is concerned with. ${ }^{85}$ However, Bucher argues that it is not a neutral metaphor and asks '[w] hat is gained and what is lost when we draw on the metaphor of the black box to describe algorithms?' ${ }^{86}$ It renders the unknown an epistemological problem, which brings it into orbit of the Enlightenment idea that more information leads to better decisions. ${ }^{87}$ As such, the metaphor suggests that, given the right resources, algorithms are knowable in principle and we are better for it. ${ }^{88}$ It spurs people on to open the black box. At the same time, it enables the 'strategic harnessing of ignorance', allowing actors to insist that the adverse effects of algorithms could not have been detected due to a lack of the right resources. ${ }^{89}$ This becomes especially problematic when experts advance such claims, which legitimates the view that nobody could know. ${ }^{90}$ The metaphor of the black box is therefore a political claim. Crucially then, even if the black box metaphor is used to challenge formal bias in the source code of algorithms, it can simultaneously validate certain aspects of it such as the distinction between experts and laypeople, highlighting the emancipation paradox formulated by Azmanova.

\footnotetext{
${ }^{80}$ Ibid., 129.

${ }^{81}$ Ibid., 138-142.

82 Ibid., 142-147.

${ }^{83}$ Ibid., 154-156.

84 Ibid., 41.

85 Ibid., 45.

86 Ibid., 44.

${ }^{87}$ Ibidem.

88 Ibid., 43.

${ }^{89}$ Ibid., 56.

90 Ibid., 57.
} 
Bucher's work on algorithms brings into view the manifold ways in which the technosystem reproduces and changes in the various settings that people encounter technologies. Even with the same technology, like the Facebook newsfeed algorithm, the setting shapes how it is negotiated and challenged. The home and the newsroom lead to different encounters and concerns. Importantly, her work shows that 'power and politics are never reducible to question of materiality or perception, but rather about making algorithms matter in specific ways and for specific purposes'. ${ }^{91}$ This includes the resources used to contest the formal bias encoded in technologies.

\section{Conclusion}

Feenberg shows in his book the importance of public interventions over technology as they highlight the inextricable link of instrumental reason to normative aspects of the lifeworld. They provide the levers for progress, which is both technical and moral. ${ }^{92}$ It is comforting to know that transcendence of existing circumstances can take a rational structure and a technological form. Public interventions can set technological development on a whole different trajectory, one that is more responsive to human needs. As such, they can even expose and question the formal bias of the capitalist system encoded in the technological infrastructure of society. This is not guaranteed, however. It requires a conscious effort to interrogate and change the very language in which contestation can proceed as Bridle's and Bucher's works demonstrate. A critical constructivist approach to the technosystem remains incomplete without theoretical and methodological tools to facilitate the challenge of the reified categories that enable formal bias to persist in that language. Only then will the critique of instrumental reason by the early thinkers of the Frankfurt School fully come to fruition in our present times. And with it a critical theory of the technosystem.

Open Access This article is distributed under the terms of the Creative Commons Attribution 4.0 International License (http://creativecommons.org/licenses/by/4.0/), which permits unrestricted use, distribution, and reproduction in any medium, provided you give appropriate credit to the original author(s) and the source, provide a link to the Creative Commons license, and indicate if changes were made.

\section{References}

Azmanova A (2012) The scandal of reason: a critical theory of political judgement. Columbia University Press, New York

Azmanova A (2020) Capitalism on edge: how fighting precarity can achieve radical change without crisis or utopia. Columbia University Press, New York

Bridle J (2018) New dark age: technology and the end of the future. Verso, London and New York

Bucher T (2018) If...then: algorithmic power and politics. Oxford University Press, New York

Chari A (2015) A political economy of the senses. Columbia University Press, New York

Feenberg A (2017) Technosystem: the social life of reason. Harvard University Press, Cambridge and London Greenfield A (2018) Radical technologies: the design of everyday life. Verso, London and New York

Koopman C (2013) Genealogy as critique: Foucault and the problems of modernity. Indiana University Press, Bloomington and Indianapolis

Lemke T (2019) A critique of political reason: Foucault's analysis of modern governmentality. Verso, London and New York

\footnotetext{
${ }^{91}$ Ibid., 18, emphasis removed.

92 Feenberg 2017, 203.
} 